\title{
A SIMULATION-BASED DEA FRAMEWORK TO IMPROVE CUSTOMER'S WAITING TIME AT VEHICLE INSPECTION CENTRE
}

\author{
Nur Syamimi Khir Johari ${ }^{1}$, Norazura Ahmad ${ }^{2}$, Norhaslinda Zainal Abidin ${ }^{3}$ \\ ${ }^{1,2,3}$ School of Quantitative Sciences, UUM College of Arts and Sciences, \\ Universiti Utara Malaysia,06010 Sintok, Kedah, Malaysia. \\ *Corresponding E-mail : nursyamimikj@gmail.com
}

\begin{abstract}
A long queue and waiting time have become the most common issue that usually happened at service industry. Similarly, in a vehicle inspection centre (VIC), a higher quality of service is measured by a short and acceptable waiting time. Typically, the long waiting time among customers is resulted by some factors, which are customer arrivals, human factors, and maintenance strategy. However, this study only focuses on customer arrival factor that contributed to this problem. This paper is a review of work based on a study conducted at VIC in Selangor, Malaysia. A framework of simulation-based DEA model is proposed to determine the most efficient strategy to reduce the problem of customer waiting time at VIC. The developed framework aims to help the management in decision making to improve the operation of the VIC current system in future.
\end{abstract}

Keywords: Vehicle Inspection Centre, Discrete Event Simulation, Data Envelopment Analysis DOI: https://doi.org/10.30880/jtmb.2018.05.02.004

\subsection{Introduction}

In every service industry, every customer wants to avoid long waits whereas service providers want to minimize the idle time and the use of overtime. Determining a reasonable waiting time at service industry is crucial as it linked with that customer satisfaction toward the services (Abd Manaf et al. 2011; Atinga, Abekah-Nkrumah, and Domfeh 2011; Garcia et al. 2012; Gharahighehi et al. 2016). The problem of long waiting time has become a concern to many researchers towards finding the solution to improve the customer waiting time (Chen et al., 2010; Gijo, Antony, Hernandez, \& Scaria, 2013; Harding, Leggat, Bowers, Stafford, \& Taylor, 2013; Sarkar, Mukhopadhyay, \& Ghosh, 2011).

VIC is one of the service industry that recently received the same concern related to the customer waiting time (Al-Saleh 2011; Ibrahim et al. 2012; Samah, Ilyas, and Majid 2014). The aim of the operation of VIC is to give a safety vehicle inspection and also to ensure the safety of road transportation. Every vehicle inspection centre wants to avoid long customer waiting time in the seeks of customer satisfaction. Currently, the key performance indexed (KPI) for customerwaiting time at any VIC is between 20 to 30 minutes. As the customer satisfaction is one of the priorities at VIC, VIC must follow the set KPI as well as possible to avoid any penalties from authority.

As the numbers of vehicles on road today are increasing compared to years back, the demand of provided service by the VIC is also increased. The data on the number of vehicles in Malaysia from 2010 to 2015 is shown in Fig. 1. The increasing number of vehicles has inspired the researchers to investigate the problems arise at VIC and finding the solution to the problem. 


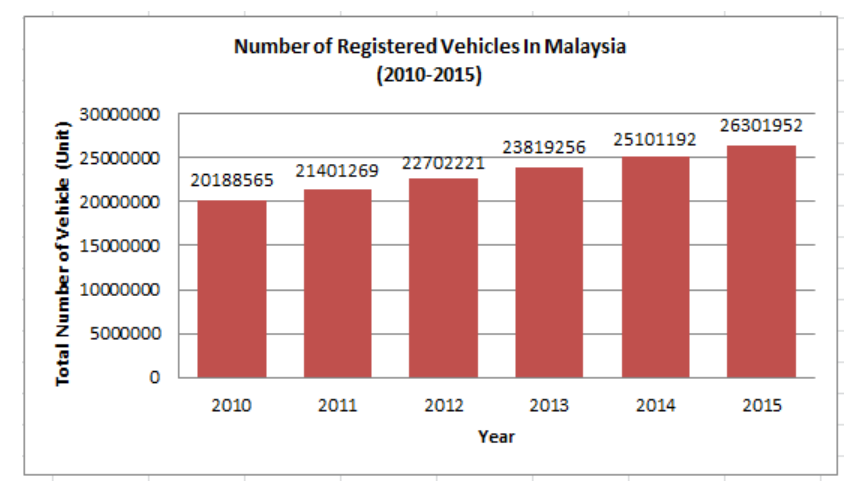

Figure 1: Number of Registered Vehicles in Malaysia from 2010-2015

Source: Road and Transportation Department (RTD), (2017)

From the literatures, long waiting time has become one of the main problems arise at VIC and simulation has been the popular method to solve the problem of customer dissatisfaction toward the given services (Al-Saleh 2011; Ibrahim et al. 2012; Samah, Ilyas, and Majid 2014). One of the appropriate methods that able to help in solving problem related to long waiting time is Discrete Event Simulation (DES) method (Gharahighehi et al. 2016). DES is a simulation method that used to characterize and to analyze the queues and interaction within the system (Siebers et al. 2010). A number of studies related to waiting time at VIC have been found in the literatures. For instance, Samah et al.(2014) identify the influence factors on the long customer waiting time at VIC. Finding from the study found that maintenance strategy is one of the factors contributed to customer waiting time. Besides, Ibrahim et al. (2012) built a DES simulation model to analyze the appointment system of VIC. An analysis of analytical work was done using spreadsheet followed by a development of simulation of service scheduling to reduce waiting time and to avoid clash between vehicles. Moreover, Al-Saleh (2011) proposed a DES method to simulate the motor vehicle inspection station and to predict the changes that might occur at inspection lanes. Eventhough DES is a potential method to minimize the waiting time problem at VIC, however DES is not able to provide determination of the best alternative for decision-making. To overcome the limitation, it is necessary to search for a method to find the most efficient strategy to reduce waiting time.

On the other hand, Data Envelopment Analysis is a linear programming method that can access the efficiency of multiple decision making units (DMU). The performance measure of DEA is called as relative efficiency, which is the sum of the weighted outputs divided by the sum of the weighted inputs (Ertay and Ruan 2005). Due to the ability of DEA to assess efficiency, it has been widely used in many study organizations, such as banks, airlines, hospitals, and manufacturing (Al-Refaie et al. 2014).

DES is a known method that able to handle "what-if" interaction of various components and processes while DEA will measure the efficiency of strategies from the simulation output analysis. DEA is a decision making tool to determine the best scenario from the potential scenarios. It has been found from the literatures that DES and DEA have been used to solve the problem on waiting time. For instance, Al-Refaie et al. (2014) applied DES and DEA approach to reduce the waiting time at emergency department (ED) and the finding of the study also helps to increase the number of patients served. Furthermore, Weng et al. (2011) developed simulation and DEA model to determine the best performing operation across multiple alternatives. The finding of the study also helps in minimizing the cost and waiting time while increases the patient satisfaction level. Besides, Van Den Bergh et al. (2013) used DES and DEA approach to solve the personal scheduling of aircraft line maintenance. Moreover, Pjevcevic et al. (2013) presented simulation and DEA method to perform the analysis of proposed scenarios for dry bulk cargo handling. Based on the reviews, it shows that the integration of DES and DEA methods is a 
beneficial method to to determine the most efficient strategy to reduce the problem of customer waiting time at VIC.

This paper consists of five sections. The next section provides the problem statement and the objective of the research followed by the research framework implemented. Lastly, the expected result is explained at the end of this paper.

\subsection{Problem Statement}

One of the issues that related to long customer waiting time is on arrival issue, where the arrival rate is higher than the service rate. Generally, VIC received about 20 units of vehicles in an hour, but the average total vehicles that can be inspected are only 10 units. The sequence of VIC processes for this study is illustrated in Fig. 2. Customer arrives at VIC either through appointment or walk in. Upon arrival, the customer needs to make a registration and payment before queueing for the inspection processes. The VIC process end when the result of inspection is released.

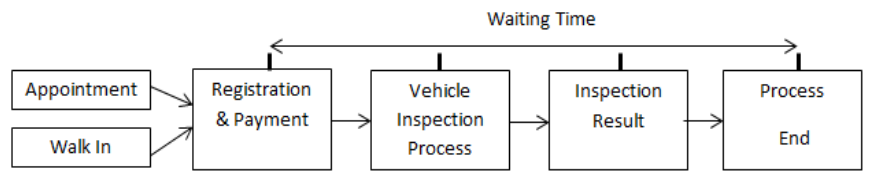

Figure 2: Sequences of VIC processes

The waiting time in this study is the time spent by a customer, starting from the registration of vehicle until the inspection process end. Usually, the problem of long waiting time due to customer arrival factor happens when there are a lot of vehicles enter the VIC. Then, it will increase the queue before they receive services from vehicle examiner (VE). This issue will be critical especially if there are many vehicles that need to be inspected during the peak time. Besides, the unpunctuality of customer on service appointment will also contribute to long waiting time issue. When the problems happened, the customer waiting time will exceed 20 minutes and this phenomena will disturb the other customer waiting time.

In this study, there are four types of inspection processes that have been considered which are routine, re-routine, transfer ownership, and special. The description of every inspection processes are shown in Table 1. On the other hand, Fig. 3 shows the average of waiting time for different type of inspections for a normal month (non-festive month). It shows that the average waiting time for every inspection processes are above 30 minutes, which means they exceed the maximum KPI of the waiting time. Thus, the problem of long waiting time is confirmed arises at VIC and the future study need to be done to reduce the problem from continuing happened.

Table 1: Types of Inspection Processes

\begin{tabular}{|c|c|}
\hline $\begin{array}{l}\text { Type of } \\
\text { Inspection }\end{array}$ & Description \\
\hline Routine & $\begin{array}{l}\text { Half year inspection to ensure compliance with Road } \\
\text { Transport Act } 1987 \text { for commercial vehicle. }\end{array}$ \\
\hline Re-routine & $\begin{array}{l}\text { Re-routine is re-inspection after failing a part of } \\
\text { inspection. }\end{array}$ \\
\hline $\begin{array}{l}\text { Transfer } \\
\text { Ownership }\end{array}$ & Prior to ownership transfer. \\
\hline Special & To determine roadworthiness of modified vehicle. \\
\hline
\end{tabular}




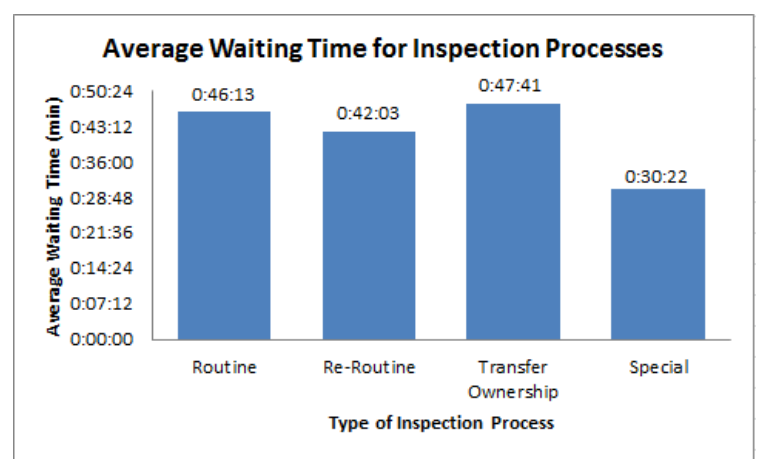

Figure 3: Average Waiting Time for Inspection Processes

\subsection{Objective}

The objective of this paper is to develop a framework of simulation-based DEA model to improve the waiting time of VIC. A real case study of vehicle inspection centre at Selangor is chosen and investigated using a proposed framework to assess the operational efficiency and increase the performance of VIC.

\subsection{Framework}

The framework of simulation-based DEA model consists of seven stages as shown in Fig. 4.

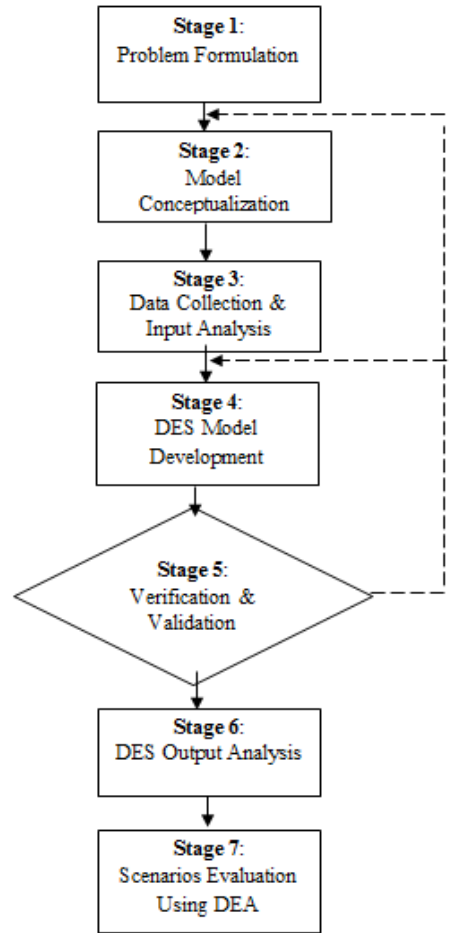

Figure 4: Framework of Study

The detail of every stage in this framework is described below:

\section{Stage 1: Problem Formulation}

The problem of this study is defined through the interview session with the branch manager and staff of VIC. Besides, the VIC operation and inspection activities at every lane and checkpoint are observed. From the interview and observation, the major cause of the long waiting time is identified. This factor will further investigate in this study. 


\section{Stage 2: Model Conceptualization}

A sketch of a simple model of VIC is developed as a simplified representation of the real situation of VIC. The location, entities, arrival, and process of the VIC model will be identified.

\section{Stage 3: Data Collection}

The data needed for this study consist of primary and secondary data. The primary data are collected through interview sessions with VIC branch manager and staff. Besides, the observation of inspection operation and the layout of VIC, customer inter-arrival time and service time at the registration counter and inspection lane are conducted. Besides, the secondary data are collected from the past documents and records of VIC. The data needed for this study are (1) the flow of of operation (2) the layout of VIC Padang Jawa, (3) customer inter-arrival time and (4) service time of every inspection process. The data collected will be analysed and interpreted before developing the VIC simulation model.

\section{Stage 4: DES Model Development}

The VIC model will build in stages until the model representing the real system of VIC using Arena simulation packages is produced. The suitable distribution to be included in the model for arrival and services will be generated using the Arena input analyzer.

\section{Stage 5: Verification and Validation}

After DES model has been developed, the verification and validation process will be carried out. Verification concerns about the operation model to determine the model is performing correctly (Law and Kelton 1991). The simulation model will be run under a variety of input parameters and then the output will be checked either the reasonable produced. Meanwhile, validation is the process of determining whether the simulation model is accurately representing the real system (Law and Kelton 1991). For this study, VIC simulation model will be validated using expert opinion. This method needs expert opinion such as branch manager to verify the simulation model, whether it represents the process of the real VIC system.

\section{Stage 6: Output Analysis}

After the simulation is run with some replications, the output analysis of the simulation model are collected and analysed. The current operation and current average waiting time of VIC is determined and analysed. Using what-if interaction, the different scenarios that could improve the performance and customer waiting time at VIC will be identified.

\section{Stage 7: Scenarios Evaluation Using DEA}

Next, based on the result obtain from DES model, DEA then is used to find the most efficient scenario to reduce the waiting time. Based on the DEA approach, the input and output of variable must be identified. In this study, the input is the number of vehicle arrives in an hour and the output is the average customer waiting time. The different scenario will be compared and the best scenario for the study will be determined. The model that will reduce the most waiting time will be proposed to the management of VIC. 


\subsection{Expected Result}

The expected outcomes from the framework are determined below.

1. The current operation of VIC will be identified.

2. A DES model of VIC will be developed.

3. The best scenario to improve the waiting time from the DEA method will be identified.

By implementing the framework, the current operation of VIC is hoped to be improved and the suitable strategy to reduce the customer waiting time will be determined at the end of the study.

\section{Acknowledgement}

This study is based on work supported under Research Grant Scheme (FRGS-13570). 


\section{References}

Abd Manaf, N. H., Abdullah, A., Abu Bakar, A., Ali, R. , Bidin, N., \& Ismail, W. (2011). Hospital waiting time: the forgotten premise of healthcare service delivery? International Journal of Health Care Quality Assurance, 24(7), 506-522.

Al-Refaie, A., Fouad, R. H., Li, M. H., \& Shurrab, M. (2014). Applying simulation and DEA to improve performance of emergency department in a Jordanian hospital. Simulation Modelling Practice and Theory, 59-72.

Al-Saleh, K. S. (2011). Productivity improvement of a motor vehicle inspection station using motion and time study techniques. Journal of King Saud University - Engineering Sciences, 23(1), 33-41.

Atinga, R. A., Abekah-Nkrumah, G., \& Domfeh, K. A. (2011). Managing healthcare quality in Ghana: a necessity of patient satisfaction. International Journal of Health Care Quality Assurance, 24(7), 548563.

Chen, B. L., Li, E. D., Yamawuchi, K., Kato, K., Naganawa, S., \& Miao, W. J. (2010). Impact of adjustment measures on reducing outpatient waiting time in a community hospital: Application of a computer simulation. Chinese Medical Journal, 123(5), 574-580.

Ertay, T., \& Ruan, D. (2005). Data envelopment analysis based decision model for optimal operator allocation in CMS. European Journal of Operational Research, 164(3), 800-810.

Garcia, D., Archer, T., Moradi, S., \& Ghiabi, B. (2012). Waiting in vain: Managing time and customer satisfaction at call centers. Journal Psychology, 3(2), 213-216.

Gharahighehi, A., Kheirkhah, A. S., Bagheri, A., \& Rashidi, E. (2016). Improving performances of the emergency department using discrete event simulation, DEA and the MADM methods. Digital Health, $2(0), 1-14$.

Gijo, E. V., Antony, J., Hernandez, J., \& Scaria, J. (2013). Reducing patient waiting time in a pathology department using the Six Sigma methodology. Leadership in Health Services, 26(4), 253-267.

Harding, K. E., Leggat, S. G., Bowers, B., Stafford, M., \& Taylor, N. F. (2013). Reducing waiting time for community rehabilitation services: A controlled before-and-after trial. Physical Medicine and Rehabilitation, 94(1), 23-31.

Ibrahim, N. K., A.Samah, A., Hasan-Basari, A. S., Asmai, S. A., \& Yusof, N. (2012). Scheduling for Vehicle Inspection Based on Specific Constraints and Simulation. Middle East Journal of Scientific Research, 12(5), 613-618.

Law, A. M., \& Kelton, W. D. (1991). Simulation modeling and analysis 2nd edn. McGrawHill New York.

Pjevcevic, D., Vladisavljevic, I., \& Vukadinovic, K. (2013). Analyzing the Efficiency of Dry Bulk Cargo Handling at the Inland Port Terminal Using Simulation and DEA, Logistics International Conference, $1(0)$.

Samah, A. A., Ilyas, K., \& Majid, H. A. (2014). Evaluating Maintenance Strategy using Discrete Event Simulation to Sustain Customer Waiting Time at Vehicle Inspection Centre, (9002), International Conference on Industrial Engineering and Operations Management ,1088-1098.

Sarkar, A., Mukhopadhyay, A. R., \& Ghosh, S. K. (2011). Improvement of service quality by reducing waiting time for service $19^{\text {th }}$ edn. Elsevier BV, 1689-1698.

Siebers, P. O., Macal, C. M., Garnett, J., Buxton, D., \& Pidd, M. (2010). Discrete-event simulation is dead, long live agent-based simulation. Journal of Simulation, 4(3), 204-210.

Van Den Bergh, J., De Bruecker, P., Beliën, J., De Boeck, L., \& Demeulemeester, E. (2013). A three-stage approach for aircraft line maintenance personnel rostering using MIP, discrete event simulation and DEA. Expert Systems with Applications, 40(7), 2659-2668.

Weng, S.J., Tsai, B.S., Wang, L.M., Chang, C.Y., \& Gotcher, D. (2011). Using simulation and data envelopment analysis in optimal healthcare efficiency allocations. Proceedings of the 2011 Winter Simulation Conference, 1295-1305. 